\title{
Crystal structure and physical properties of $\mathrm{UMo}_{3} \mathbf{B}_{7}$
}

\author{
L. Salamakha ${ }^{1}$, O. Sologub ${ }^{1, *}$, C. Rizzoli ${ }^{2}$, H. Michor ${ }^{1}$, \\ A. P. Gonçalves ${ }^{3}$, P. $\operatorname{Rog}^{4}$, E. Bauer ${ }^{1}$ \\ ${ }^{1}$ Institute of Solid State Physics, TU Wien, A-1040 Wien, Austria \\ ${ }^{2}$ Dipartimento di Chimica, Università degli Studi di Parma, Parco Area delle Scienze \\ 17/A, 43124 Parma, Italy \\ ${ }^{3} C^{2} T N$, Instituto Superior Técnico, Universidade de Lisboa, Estrada Nacional 10, \\ 2695-066 Bobadela LRS, Portugal \\ ${ }^{4}$ Institute of Materials Chemistry and Research, University of Vienna, A-1090 Vienna, \\ Austria
}

\begin{abstract}
A novel ternary compound, $\mathrm{UMo}_{3} \mathrm{~B}_{7}$, has been synthesized by arc melting and annealing at $900{ }^{\circ} \mathrm{C}$. Its crystal structure was determined from X-ray single crystal diffraction data $\left(\mathrm{YMo}_{3} \mathrm{~B}_{7}\right.$-type structure, space group Pnma; $a=1.10310(8) \mathrm{nm}$, $\left.b=0.30995(2) \mathrm{nm}, c=1.2792(1) \mathrm{nm}, \mathrm{R}_{\mathrm{F}}^{2}=0.0205\right)$. The structure is composed of boron filled trigonal prisms as well as unfilled tetrahedra and tetragonal pyramids formed by metal atoms. With respect to boron atoms aggregation, it exhibits a well-developed two-dimensional boron network revealing infinite bands of edge linked boron hexagons. The relationship with the members of the structural series within the V-B system: $\mathrm{V}_{\mathrm{n}} \mathrm{B}_{\mathrm{n}+1}=(\mathrm{n}-1) \mathrm{VB}(\mathrm{CrB}$-type $)+\mathrm{VB}_{2}\left(\mathrm{AlB}_{2}\right.$-type $)(\mathrm{n}=1,2,3,5)$ is discussed. Specific heat, magnetic susceptibility and electrical resistivity measurements characterizes $\mathrm{UMo}_{3} \mathrm{~B}_{7}$ as a spin fluctuating system.
\end{abstract}

Keywords: uranium molybdenum boride; crystal chemistry; electrical resistivity; magnetic susceptibility; specific heat; X-ray diffraction.

\footnotetext{
* Corresponding author.

E-mail address: oksana.sologub@univie.ac.at (O. Sologub)
} 


\section{Introduction}

Among boron rich borides, compounds with structures based on boron nets have triggered considerable scientific attention due to the important role of boron networks for distinct physical properties. Two-dimensional networks of boron atoms have been found in various structures including (i) $\mathrm{MgB}_{2}$ with metal layers sandwiched by planar boron honeycomb layers, which were also reported to play an important role for the superconducting behaviour of this compound [1,2], (ii) heavy fermion superconductor $\beta$ - $\mathrm{YbAlB}_{4}$ exhibiting $\mathrm{Yb}$ and $\mathrm{Al}$ atoms located in the interlayer space of planar $\mathrm{B}_{5^{-}}$and $\mathrm{B}_{7^{-}}$rings [3-7], (iii) $\mathrm{Y}_{2} \mathrm{ReB}_{6^{-}}$-type structure where the planar nets are formed by $\mathrm{B}_{5^{-}}, \mathrm{B}_{6^{-}}$and $\mathrm{B}_{7}$ rings [8], (iv) structures with puckered nets of squares, pentagons, heptagons and irregular polygons, etc. [9]. The structures of boron rich compounds of $f$-element - transition metal - boride systems are also rewarding subjects for elucidating the structural modifications and defects which play an important role for, e.g., structure stabilization of $\mathrm{Mg}_{2} \mathrm{M}_{0.75} \mathrm{~B}_{6.50}(\mathrm{M}=\mathrm{Rh}$, Ir $)[10,11]$, or, for instance, low temperature magnetic anomalies of $\mathrm{TmAlB}_{4}$ [12-14].

Earlier investigations of uranium molybdenum borides [15] defined the crystal structures of two ternary phases: $\mathrm{UMoB}_{4}$ with $\mathrm{ThMoB}_{4}$-type structure, space group Cmmm [16] and $\mathrm{U}_{2} \mathrm{MoB}_{6}\left(\mathrm{Y}_{2} \mathrm{ReB}_{6}\right.$-type structure, space group Pbam $)$ [17]. Later on, a new $\mathrm{U}_{5} \mathrm{Mo}_{10} \mathrm{~B}_{24}$ structure (own structure type, space group Pmmn) which exhibits three kinds of boron polyanions - two-dimensionally infinite, puckered sheets consisting of six- and eight-membered rings; planar ribbons of condensed $\mathrm{B}_{6}$-rings; chains of condensed $\mathrm{B}_{8}$-rings - was discovered by Konrad and Jeitschko [18]. Although it was believed that $\mathrm{U}_{5} \mathrm{Mo}_{10} \mathrm{~B}_{24}$ corresponds to $" \mathrm{UMo}_{2} \mathrm{~B}_{6}$ ", reported by Kuz'ma et al. [15], in the course of our exploration of the boron-rich region of the UMo-B isotherm at $900{ }^{\circ} \mathrm{C}[19]$, we observed and studied a new compound $\mathrm{UMo}_{3} \mathrm{~B}_{7}$, for which we present herein the crystal structure obtained from X-ray single crystal diffraction data and results of low temperature heat capacity, magnetic susceptibility and electrical resistivity studies.

\section{Experimental details}

Several samples within the 8U:30Mo:62B - 11U:22Mo:67B composition range and a total amount of about $0.5 \mathrm{~g}$ each were prepared by argon arc-melting elemental pieces of uranium (purity $>99.9 \%$ ), molybdenum $(99.95 \%$ ) and crystalline 
boron (purity $>99.8 \%$ ). The surface of uranium pieces was deoxidized in diluted nitric acid prior to melting. The samples were re-melted several times without significant weight losses $(<1 \mathrm{wt} . \%)$. The alloy buttons were sealed in evacuated quartz tubes and annealed at $900{ }^{\circ} \mathrm{C}$ for two weeks before quenching into cold water. X-ray powder diffraction patterns were collected employing a Philips X'Pert diffractometer with $\mathrm{Cu}$ $\mathrm{K}_{\alpha}$ radiation within the $2 \theta$ range 10-120 deg. Evaluation with the WINPLOTR [20] and FULLPROF [21] programs indicated the formation of a new compound at the approximate composition 9U:27Mo:64B.

$\mathrm{YMo}_{3} \mathrm{~B}_{7}(\sim 1 \mathrm{~g})$ was prepared from pieces of pure elements (Y 99.9\%, Mo $99.95 \%$ and $\mathrm{B}>99.8 \%$ ) following the above-described procedure. X-ray powder diffraction data were collected employing a Guinier-Huber Image Plate system with monochromatic $\mathrm{Cu} \mathrm{K \alpha} \alpha_{1}$ radiation $\left(8^{\circ}<2 \theta<100^{\circ}\right)$.

Several crystals were mechanically isolated from the crushed $\mathrm{U}_{11} \mathrm{Mo}_{22} \mathrm{~B}_{67}$ nominal composition alloy and their crystal structure was investigated with the help of a Bruker AXS SMART CCD diffractometer. Inspection of the first 20 frames of single crystal diffraction data assured high crystal quality, unit cell dimensions and orthorhombic Laue symmetry of the specimens prior to the X-ray intensity data collections. The data set for the best crystal was recorded at room temperature in the $\omega$-scan mode. A total of 2464 frames were collected with a $\Delta \phi$ of $0.3^{\circ}$ and an exposure time of $30 \mathrm{~s}$. Data reduction was carried out using the SAINT suite of programs; the intensities were corrected for absorption with the assistance of the program SADABS [22]. Further details of data collection are provided in Table 1. Structure solution and refinement were performed with SHELXS-97 and SHELXL-97 from the WinGX-1.70.00 integrated systems of programs [23, 24].

Physical properties have been studied for the two isostructural compounds, $\mathrm{UMo}_{3} \mathrm{~B}_{7}$ and $\mathrm{YMo}_{3} \mathrm{~B}_{7}$. A superconducting quantum interference device (SQUID) served for magnetization measurements in the temperature interval from 3 to $300 \mathrm{~K}$ using bar-shaped polycrystalline specimens of about $20 \mathrm{mg}$. Specific heat measurements on samples of about the same weight were performed at temperatures ranging from $2 \mathrm{~K}$ up to $20 \mathrm{~K}$ by means of the conventional relaxation time method in a Quantum Design PPMS. The electrical resistivity of bar shaped samples (about $1 \times 1 \times 5 \mathrm{~mm}^{3}$ ) was measured using a four-probe a.c.-bridge method in the temperature range from $0.4 \mathrm{~K}$ to room temperature and in fields up to $12 \mathrm{~T}$ [25]. 


\section{Crystal structure determination and analysis}

Single crystal X-ray intensity pattern indicated a primitive orthorhombic lattice, Laue class $\mathrm{mmm}$ and systematic extinctions consistent with space group Pnma (no. 62). Initial atomic positions for one uranium atom and three molybdenum atoms were found by direct methods, whereas seven boron atoms were located from difference Fourier synthesis. The refinement of the structure proceeded straight-forwardly adopting anisotropic temperature factors for the metal atoms but isotropic thermal displacement parameters for boron atoms (Table 1) and led to a residual value as low as $\mathrm{R}_{\mathrm{F}}^{2}=0.0205$. Standardization of the atomic positions with program Structure Tidy [26] confirmed isotypism with the structure model of $\mathrm{YMo}_{3} \mathrm{~B}_{7}$ [27]. Good agreement with the parent structure was also observed for the values of interatomic distances $\left(\mathrm{d}_{\mathrm{U}}\right.$ $\mathrm{U}=0.30995(2) \mathrm{nm}$ and $\mathrm{d}_{\mathrm{Y}-\mathrm{Y}}=0.3101 \mathrm{~nm}$; B-B distances range from 0.1759(9) nm for B1-B4 to 0.1843(9) nm for B3-B6, etc.) (Table 2). The coordination numbers of metal atoms were found to be 22 for uranium and 15, 17 and 20 for Mo1, Mo2 and Mo3 respectively: $\left[\mathrm{UB}_{12} \mathrm{Mo}_{8} \mathrm{U}_{2}\right]$, $\left[\mathrm{Mo}_{1} \mathrm{~B}_{9} \mathrm{Mo}_{4} \mathrm{U}_{4}\right]$, $\left[\mathrm{Mo} 2 \mathrm{~B}_{9} \mathrm{Mo}_{5} \mathrm{U}_{3}\right]$ and $\left[\mathrm{Mo}_{3} \mathrm{~B}_{12} \mathrm{Mo}_{7} \mathrm{U}\right]$. A three dimensional view of the $\mathrm{UMo}_{3} \mathrm{~B}_{7}$ structure is shown in Figure 1. Boron atoms are bonded to form slightly puckered bands composed of six rows of edge-linked hexagons extended infinitely in the $b$ direction and tilted to the $a b$-plane. All boron atoms are placed in triangular prisms formed by metal atoms with three (for B1, B2, B3, B4, B5 and B6) or two (for B7) additional atoms of boron located against triangular faces. In $\mathrm{UMo}_{3} \mathrm{~B}_{7}$, the trigonal $\left[\mathrm{BM}_{6}\right]$ prisms $(\mathrm{M}=\mathrm{U}, \mathrm{Mo})$ share triangular (and rectangular) faces to form slabs running infinitely along the $b$ axis. In the $a c$ plane, the slabs are separated by infinite columns of unfilled tetrahedra $\left[\mathrm{Mo}_{2} \mathrm{U}_{2}\right]$ and tetragonal pyramids $\left[\mathrm{Mo}_{4} \mathrm{U}\right]$. These three structural units also constitute the structure of $\mathrm{CrB}$ [28] (Figure 2c), which is composed, in terms of structural fragments, of Wtype slabs (infinite planar layers of face-linked unfilled tetrahedra and tetragonal pyramids formed by $\mathrm{Cr}$ atoms) inter-leaving with $\mathrm{AlB}_{2}$-type slabs (B-filled trigonal prisms $\left[\mathrm{BCr}_{6}\right]$ (Figure $2 \mathrm{~b}$ ) as well as they form the structures of related monoborides $\mathrm{FeB}, \alpha-\mathrm{MoB}$ and their ternary derivative $\mathrm{NbCoB}_{2}$. Boron atoms in these structures form infinite zigzag boron chains. In numerous structures with metal/boron ratios larger than 1.5, two or three B zigzag chains are connected at bonding distances thus forming double or triple chains [9]. This tendency toward two-dimensional net 
formation (e.g. $\mathrm{AlB}_{2}$-type) with increasing boron content is recognized from the structural series within the V-B system: $\mathrm{V}_{\mathrm{n}} \mathrm{B}_{\mathrm{n}+1}=(\mathrm{n}-1) \mathrm{VB}(\mathrm{CrB}$-type $)+\mathrm{VB}_{2}\left(\mathrm{AlB}_{2}-\right.$ type) $(n=1,2,3,5)$ [29]. In $V_{2} B_{3}$ (Figure $2 d$ ), three $B$ zigzag chains are connected to form planar bands of $\mathrm{B}_{6}$ hexagons extending infinitively along the $c$ axis; correspondingly the structure is composed of slabs of three layers of close packed $\left[\mathrm{BV}_{6}\right]$ trigonal prisms. Two slabs are inter-linked via unfilled rectangular pyramids and tetrahedra formed by vanadium atoms. In $\mathrm{UMo}_{3} \mathrm{~B}_{7}$, the slabs are composed of 7 layers of slightly distorted $\left[\mathrm{BM}_{6}\right]$ trigonal prisms and terminate with the columns of rectangular pyramids and tetrahedra (Figure 2a). Contrary to the $V_{2} B_{3}$ structure, the slabs are shifted with respect to each other along the $x$-axis; each column is linked via U-Mo bonds with another column, which in turn gives rise for a new slab built of 7 layers of $\left[\mathrm{BM}_{6}\right]$ trigonal prisms. Condensation of prisms in the ac plane is realized by metal-metal bonds in such a way that every consequent corrugated layer is composed of only trigonal prisms connected by triangular-faces, while the remaining layers resemble the arrangement of fragments in the transposition structure of $\mathrm{CrB}$, the $\mathrm{FeB}$ [30] and exhibit the rectangular pyramids and tetrahedra interleaved with one or two $\left[\mathrm{BM}_{6}\right]$ trigonal prisms.

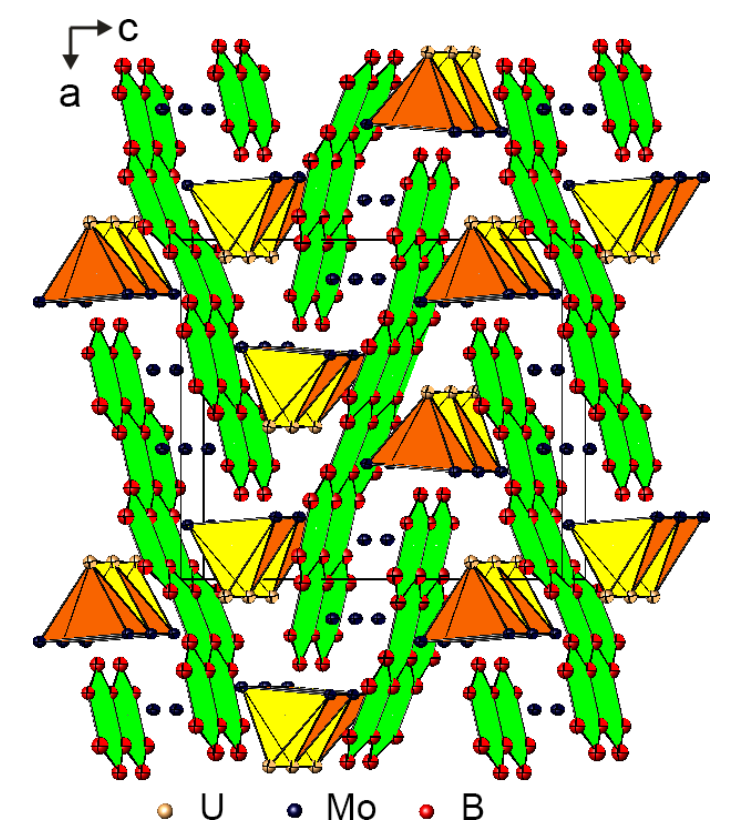

Fig. 1. Unit cell of $\mathrm{UMo}_{3} \mathrm{~B}_{7}$ emphasizing structural fragments: boron sub-lattice, and columns of unfilled tetragonal pyramids and tetrahedra formed by metal atoms. Bonds interlinking those fragments are omitted for clarity. 


\section{Table 1}

Crystal structure data ${ }^{a}$ for $\mathrm{UMo}_{3} \mathrm{~B}_{7}$ and $\mathrm{YMo}_{3} \mathrm{~B}_{7}\left(\mathrm{YMo}_{3} \mathrm{~B}_{7}\right.$-type structure, space group Pnma (no. 62), Z=4)

\begin{tabular}{|c|c|c|}
\hline Nominal composition & $\mathrm{U}_{9.09} \mathrm{Mo}_{27.27} \mathrm{~B}_{63.64}$ & $\mathrm{Y}_{9.09} \mathrm{Mo}_{27.27} \mathrm{~B}_{63.64}$ \\
\hline Formula from refinement & $\mathrm{UMo}_{3} \mathrm{~B}_{7}$ & $\mathrm{YMo}_{3} \mathrm{~B}_{7}$ \\
\hline Diffractometer & Bruker AXS SMART CCD, $\mathrm{MoK}_{\alpha}$ & Guinier-Huber Image Plate, $\mathrm{CuK}_{\alpha 1}$ \\
\hline Theta range & $7.40^{\circ}<2 \theta<69.96^{\circ}$ & $10^{\circ}<2 \theta<100^{\circ}$ \\
\hline Crystal size & $20 \times 20 \times 40 \mu m^{3}$ & - \\
\hline$a[\mathrm{~nm}]$ & $1.10310(8)$ & $1.10136(2)$ \\
\hline$b[\mathrm{~nm}]$ & $0.30995(2)$ & $0.310244(5)$ \\
\hline$c[\mathrm{~nm}]$ & $1.2792(1)$ & $1.28597(2)$ \\
\hline Reflections in refinement & $1040 \mathrm{Fo}>4 \sigma(\mathrm{Fo})$ of 1092 & 159 \\
\hline Mosaicity & $<0.4$ & - \\
\hline Number of variables & 47 & 42 \\
\hline Reliability factors & $\begin{array}{l}\mathrm{R}_{\mathrm{F}}^{2}=\Sigma \mid \mathrm{F}_{\mathrm{o}}^{2}-\mathrm{F}_{\mathrm{c}}^{2} \mathrm{l} / \mathrm{\Sigma \textrm {F } _ { \mathrm { o } }}{ }^{2}=0.0205 \\
\mathrm{wR} 2=0.0553 \\
\mathrm{GOF}=1.021 \\
-\end{array}$ & $\begin{array}{l}\mathrm{R}_{\mathrm{F}}=\Sigma\left|\mathrm{F}_{\mathrm{o}}-\mathrm{F}_{\mathrm{c}}\right| / \Sigma \mathrm{F}_{\mathrm{o}}=0.049 \\
\mathrm{R}_{\mathrm{I}}=\Sigma\left|\mathrm{I}_{\mathrm{o}}-\mathrm{I}_{\mathrm{c}}\right| / \Sigma \mathrm{I}_{\mathrm{o}}=0.073 \\
\left.\mathrm{R}_{\mathrm{exp}}=\left[(\mathrm{N}-\mathrm{P}+\mathrm{C}) / \Sigma \mathrm{w}_{\mathrm{i}} \mathrm{y}^{2}{ }_{\mathrm{oi}}\right)\right]^{1 / 2}=0.018 \\
\chi^{2}=\left(\mathrm{R}_{\mathrm{wP}} / \mathrm{R}_{\mathrm{e}}\right)^{2}=8.50\end{array}$ \\
\hline $\begin{array}{l}\text { Extinction } \\
\text { (Zachariasen) }\end{array}$ & $0.0034(2)$ & - \\
\hline $\mathrm{M}^{b} ;$ Occ.; & $x=0.44931(2), z=0.69300(2) ; 1.00 \mathrm{U} 1$; & $x=0.4501(2), z=0.6920(2) ; 1.00 \mathrm{Y} 1$; \\
\hline $\begin{array}{l}\mathrm{U}_{11}^{c, a} ; \mathrm{U}_{22} ; \mathrm{U}_{33} ; \\
\mathrm{B}_{\text {iso }} ;\end{array}$ & $\begin{array}{l}0.0040(1) ; 0.0049(1) ; 0.0044(1) \\
-\end{array}$ & $\overline{-}-44(8)$ \\
\hline Mo1; Occ.; & $x=0.31665(4), z=0.20508(2) ; 1.00$ & $x=0.3130(2), z=0.2028(2) ; 1.00$ \\
\hline $\mathrm{U}_{11} ; \mathrm{U}_{22} ; \mathrm{U}_{33}$ & $0.0030(2) ; 0.0044(2) ; 0.0042(2)$ & - \\
\hline $\mathrm{B}_{\text {iso }}$ & - & $0.42(8)$ \\
\hline Mo2; Occ.; & $x=0.33957(4), z=0.43667(4) ; 1.00$ & $x=0.3389(2), z=0.4361(2) ; 1.00$ \\
\hline $\mathrm{U}_{11} ; \mathrm{U}_{22} ; \mathrm{U}_{33}$ & $0.0028(2) ; 0.0048(2) ; 0.0037(2)$ & - \\
\hline $\mathrm{B}_{\text {iso }}$ & - & $0.58(9)$ \\
\hline Mo3; Occ.; & $x=0.88360(4), z=0.52688(4) ; 1.00$ & $x=0.8823(2), z=0.5277(2) ; 1.00$ \\
\hline $\mathrm{U}_{11} ; \mathrm{U}_{22} ; \mathrm{U}_{33}$ & $0.0032(2) ; 0.0054(2) ; 0.0046(2)$ & - \\
\hline $\mathrm{B}_{\text {iso }}$ & - & $0.74(8)$ \\
\hline B1; Occ.; & $x=0.0101(6), z=0.3635(5) ; 1.00$ & $x=0.011(3), z=0.362(2) ; 1.00$ \\
\hline $\mathrm{U}_{\text {iso }}, \mathrm{B}_{\text {iso }}$ & $0.0066(9)$ & $0.5^{e}$ \\
\hline B2; Occ.; & $x=0.0364(6), z=0.0177(5) ; 1.00$ & $x=0.039(3), z=0.018(2) ; 1.00$ \\
\hline $\mathrm{U}_{\text {iso }}, \mathrm{B}_{\text {iso }}$ & $0.0056(9)$ & $0.5^{e}$ \\
\hline B3; Occ.; & $x=0.0685(6), z=0.6154(5) ; 1.00$ & $x=0.069(2), z=0.617(2) ; 1.00$ \\
\hline $\mathrm{U}_{\text {iso }}, \mathrm{B}_{\text {iso }}$ & $0.0054(9)$ & $0.5^{e}$ \\
\hline B4; Occ.; & $x=0.1653(6), z=0.3321(5) ; 1.00$ & $x=0.166(2), z=0.333(2) ; 1.00$ \\
\hline $\mathrm{U}_{\text {iso }}, \mathrm{B}_{\text {iso }}$ & $0.0044(9)$ & $0.5^{e}$ \\
\hline B5; Occ.; & $x=0.1849(6), z=0.0685(5) ; 1.00$ & $x=0.187(2), z=0.067(2) ; 1.00$ \\
\hline $\mathrm{U}_{\text {iso }}, \mathrm{B}_{\text {iso }}$ & $0.0064(9)$ & $0.5^{e}$ \\
\hline B6; Occ.; & $x=0.2316(6), z=0.5840(5) ; 1.00$ & $x=0.230(2), z=0.582(2) ; 1.00$ \\
\hline $\mathrm{U}_{\text {iso }}, \mathrm{B}_{\text {iso }}$ & $0.0059(9)$ & $0.5^{e}$ \\
\hline B7; Occ.; & $x=0.2507(6), z=0.8262(5) ; 1.00$ & $x=0.248(2), z=0.826(3) ; 1.00$ \\
\hline $\mathrm{U}_{\text {iso }}, \mathrm{B}_{\text {iso }}$ & $0.0072(10)$ & $0.5^{e}$ \\
\hline $\begin{array}{l}\text { Residual density, max; min } \\
{\left[\mathrm{el} . / \mathrm{nm}^{3}\right] \times 10^{3}}\end{array}$ & $2.85 ;-2.19$ & - \\
\hline
\end{tabular}

${ }^{a}$ Crystal structure data are standardized using the program Structure Tidy ${ }^{25} ;{ }^{b}$ All atoms in $4 c(x, 1 / 4, z) ;{ }^{c}$ Anisotropic $\mathrm{U}_{\mathrm{ij}}$ (isotropic $\mathrm{U}_{\mathrm{iso}}, \mathrm{B}_{\mathrm{iso}}$ ) atom displacement parameters are given in $\AA^{2} ;{ }^{d} \mathrm{U}_{13}=\mathrm{U}_{23}=\mathrm{U}_{12}=0 ;{ }^{e}$ Fixed parameter 
Table 2

Selected interatomic distances $(\times 10 \mathrm{~nm})$ for $\mathrm{UMo}_{3} \mathrm{~B}_{7}$

\begin{tabular}{|c|c|c|c|c|c|c|c|}
\hline U1-2B5 & $2.670(5)$ & Mo2- B6 & $2.230(6)$ & B1- B4 & $1.759(9)$ & B4- B1 & $1.759(9)$ \\
\hline$-2 \mathrm{~B} 4$ & $2.678(5)$ & $-B 2$ & $2.230(6)$ & $-2 \mathrm{~B} 3$ & $1.796(5)$ & $-2 \mathrm{~B} 7$ & $1.807(4)$ \\
\hline$-2 \mathrm{~B} 1$ & $2.713(5)$ & $-2 \mathrm{~B} 5$ & $2.307(5)$ & - Mo1 & $2.307(7)$ & - Mo1 & $2.330(6)$ \\
\hline$-2 \mathrm{~B} 2$ & $2.729(5)$ & $-2 \mathrm{~B} 2$ & $2.313(5)$ & $-2 \mathrm{Mo} 3$ & $2.397(5)$ & - Mo2 & $2.340(6)$ \\
\hline$-B 7$ & $2.776(6)$ & $-2 \mathrm{~B} 7$ & $2.322(5)$ & - Mo3 & $2.513(6)$ & $-2 \mathrm{Mo} 3$ & $2.438(5)$ \\
\hline$-B 6$ & $2.777(6)$ & $-\mathrm{B} 4$ & $2.340(6)$ & $-2 \mathrm{U} 1$ & $2.713(5)$ & $-2 \mathrm{U}$ & $2.678(5)$ \\
\hline$-\mathrm{B} 3$ & $2.781(6)$ & $-2 \mathrm{Mo}$ & $2.9461(6)$ & & & & \\
\hline$-B 2$ & $2.863(6)$ & - Mo & $2.9733(8)$ & B2- B5 & $1.762(9)$ & B5- B2 & $1.762(9)$ \\
\hline$-2 \mathrm{U} 1$ & $3.0995(2)$ & $-2 \mathrm{Mo}$ & $3.0995(2)$ & $-2 \mathrm{~B} 2$ & $1.805(5)$ & $-2 \mathrm{~B} 6$ & $1.813(5)$ \\
\hline$-2 \mathrm{Mo} 2$ & $3.2522(5)$ & $-2 \mathrm{U} 1$ & $3.2522(5)$ & - Mo2 & $2.249(7)$ & - Mo1 & $2.271(7)$ \\
\hline$-2 \mathrm{Mol}$ & $3.2813(5)$ & - U1 & $3.4953(6)$ & $-2 \mathrm{Mo} 2$ & $2.313(5)$ & $-2 \mathrm{Mo} 2$ & $2.307(5)$ \\
\hline$-2 \mathrm{Mo1}$ & $3.3216(5)$ & & & $-2 \mathrm{U} 1$ & $2.729(5)$ & - Mo3 & $2.508(7)$ \\
\hline - Mo2 & $3.4953(6)$ & Mo3- B3 & $2.333(7)$ & - U1 & $2.863(6)$ & $-2 \mathrm{U} 1$ & $2.670(5)$ \\
\hline \multirow{2}{*}{ - Mo3 } & $3.6568(5)$ & - B7 & $2.384(6)$ & & & & \\
\hline & & $-2 \mathrm{~B} 1$ & $2.397(5)$ & B3-2B1 & $1.796(5)$ & B6-2B5 & $1.813(5)$ \\
\hline Mo1-2B6 & $2.255(5)$ & $-2 \mathrm{~B} 4$ & $2.438(5)$ & $-B 6$ & $1.843(9)$ & $-\mathrm{B} 3$ & $1.843(9)$ \\
\hline$-\mathrm{B} 5$ & $2.271(7)$ & $-2 \mathrm{~B} 3$ & $2.448(5)$ & $-2 \mathrm{Mo} 1$ & $2.307(5)$ & - Mo2 & $2.230(6)$ \\
\hline$-2 \mathrm{~B} 3$ & $2.307(5)$ & $-2 \mathrm{~B} 6$ & $2.455(5)$ & - Mo3 & $2.333(7)$ & $-2 \mathrm{Mo1}$ & $2.255(5)$ \\
\hline - B1 & $2.307(7)$ & $-\mathrm{B} 5$ & $2.508(7)$ & $-2 \mathrm{Mo} 3$ & $2.448(5)$ & $-2 \mathrm{Mo} 3$ & $2.455(5)$ \\
\hline$-2 \mathrm{~B} 7$ & $2.314(5)$ & $-\mathrm{B} 1$ & $2.513(6)$ & - U1 & $2.781(6)$ & - U1 & $2.777(7)$ \\
\hline$-\mathrm{B} 4$ & $2.330(6)$ & $-2 \mathrm{Mo} 2$ & $2.9461(6)$ & & & & \\
\hline - Mo2 & $2.9733(8)$ & - Mo1 & $3.0578(8)$ & & & B7-2B4 & $1.807(4)$ \\
\hline - Mo3 & $3.0578(8)$ & $-2 \mathrm{Mo} 3$ & $3.0772(6)$ & & & $-2 \mathrm{Mo1}$ & $2.314(5)$ \\
\hline$-2 \mathrm{Mo1}$ & $3.0995(2)$ & $-2 \mathrm{Mo} 3$ & $3.0995(2)$ & & & $-2 \mathrm{Mo} 2$ & $2.322(5)$ \\
\hline$-2 \mathrm{U} 1$ & $3.2813(5)$ & - U1 & $3.6568(5)$ & & & - Mo3 & $2.384(7)$ \\
\hline$-2 \mathrm{U} 1$ & $3.3216(5)$ & & & & & - U1 & $2.776(7)$ \\
\hline
\end{tabular}

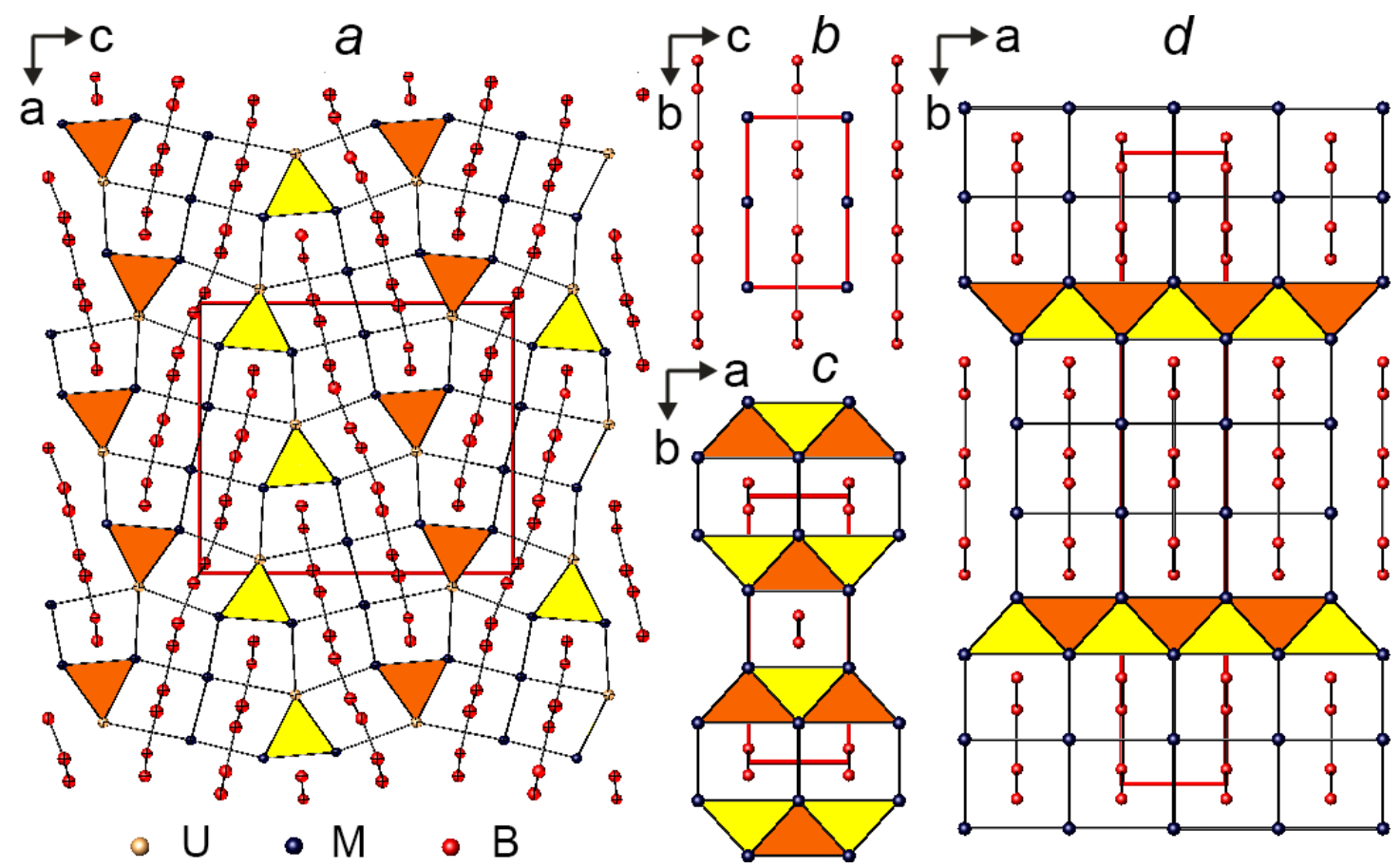

Fig. 2. $\mathrm{UMo}_{3} \mathrm{~B}_{7}$ structure (a) in comparison with $\mathrm{AlB}_{2}$ in orthorhombic setting (b), $\mathrm{CrB}(\mathrm{c})$ and $\mathrm{V}_{2} \mathrm{~B}_{3}(\mathrm{~d})$. M stays for $\mathrm{Al}, \mathrm{Cr}, \mathrm{V}$ and Mo. 


\section{Physical properties}

Figure 3 shows the temperature dependence of the electrical resistivity of $\mathrm{UMo}_{3} \mathrm{~B}_{7}$ together with the resistivity of non magnetic $\mathrm{YMo}_{3} \mathrm{~B}_{7}$. The resistivity of the latter behaves as expected for simple metals, and can be described in terms of the Bloch-Grüneisen model:

$$
\rho_{\text {ideal }}=\rho_{0}+C \frac{T^{5}}{\theta_{R}{ }^{6}} \int_{0}^{\theta_{R} / T} \frac{x^{5}}{\left(e^{x}-1\right)\left(1-e^{-x}\right)} d x
$$

where $\rho_{0}$ is the residual resistivity due to charge carrier scattering on static lattice defects and the second term represents the scattering of electrons on thermally excited phonons. Such an approach gives a Debye temperature, $\theta_{\mathrm{R}}=341 \mathrm{~K}$ and a residual resistivity value $\rho_{0}=9.5 \mu \Omega \mathrm{cm}$ as a result of a least squares fitting (solid line, Fig.3).

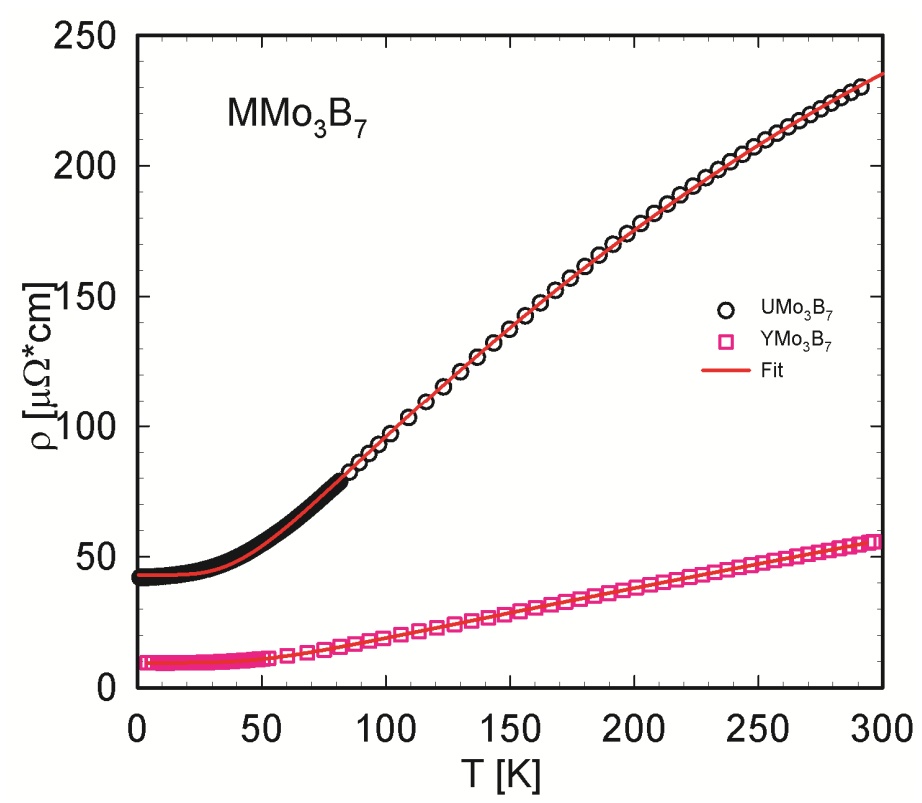

Fig. 3. Temperature dependent electrical resistivity of $\mathrm{UMo}_{3} \mathrm{~B}_{7}$ and nonmagnetic $\mathrm{YMo}_{3} \mathrm{~B}_{7}$. Solid line is a least square fit according to the Bloch-Grüneisen relation.

The resistivity of the uranium compound increases with increasing temperature demonstrating a metallic behaviour with no anomalies in the entire temperature range studied. However, in the high temperature region the resistivity of 
$\mathrm{UMo}_{3} \mathrm{~B}_{7}$ exhibits a tendency to saturate due to $s-d$ interband scattering, and thus the Bloch-Grüneisen-Mott formula

$$
\rho_{B-G-M}=\rho_{0}+C \frac{T^{5}}{\theta_{R}{ }^{6}} \int_{0}^{\theta_{R} / T} \frac{x^{5}}{\left(e^{x}-1\right)\left(1-e^{-x}\right)} d x-A T^{3}
$$

is taken into account, delivering $\rho_{0}=43 \mu \Omega \mathrm{cm}, \theta_{R}=267 \mathrm{~K}$ and a Mott coefficient, $\mathrm{A}=1.2 * 10^{-6} \mu \Omega / \mathrm{cmK}^{3}$. Despite the good agreement of the Bloch-Grüneisen-Mott formula with the experimental data in the high temperature region, in the low temperature range the resistivity of $\mathrm{UMo}_{3} \mathrm{~B}_{7}$ is no longer dominated by phonons, but rather changes towards a $\mathrm{T}^{2}$ behaviour. A similar behaviour of the resistivity is also observed in applied magnetic fields (see Figure $4 \mathrm{~b}$ ), where the $\rho(T) v s \mathrm{~T}^{2}$ curves are strictly linear for all magnetic fields in the temperature region below $10 \mathrm{~K}$.
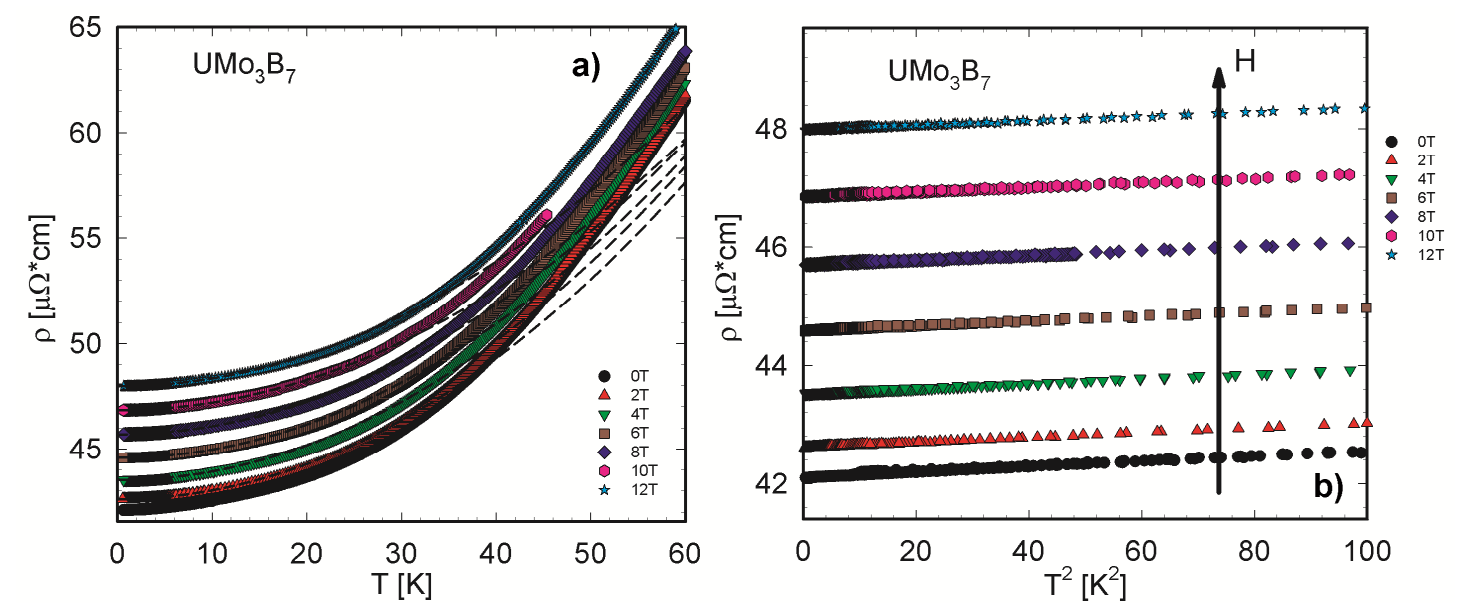

Fig. 4. a) Temperature dependent electrical resistivity of $\mathrm{UMo}_{3} \mathrm{~B}_{7}$ measured at various external magnetic fields up to $12 \mathrm{~T}$. The dashed lines correspond to $\rho(T)=\rho_{0}+A_{H} T^{2}$ fits. b) Resistivity as a function of $\mathrm{T}^{2}$ for temperatures below $10 \mathrm{~K}$.

The magnetoresistance of $\mathrm{UMo}_{3} \mathrm{~B}_{7}$ is presented on Fig. 5a in a form of $\frac{\rho(H, T)-\rho(0, T)}{\rho(0, T)}$. It is positive at all the temperatures studied (from 0.5 to $50 \mathrm{~K}$ ), monotonously increases with increasing fields and decreases as the temperature raises. Such a behaviour is a typical feature of the so called classical magnetoresistance, where the increase in resistivity with the magnetic field is understood in terms of the magnetic field driven orbital motion of conduction 
electrons. This influence should produce a $\Delta \rho_{n m r}(H, T)=A(T) H^{2}$ behaviour, where $A(T)$ decreases with increasing temperature. However this is not the case for the magnetoresistance of $\mathrm{UMo}_{3} \mathrm{~B}_{7}$, where $\frac{\rho(H, T)-\rho(0, T)}{\rho(0, T)}$ was found not to be dependent on $\mathrm{H}^{2}$, but rather follows a weaker power law, hinting to magnetic interactions producing a negative contribution to the total magnetoresistance. Moreover, the Kohler's rule is not well satisfied (see inset Fig 5a). Such a behaviour is typically found in spin fluctuating systems.
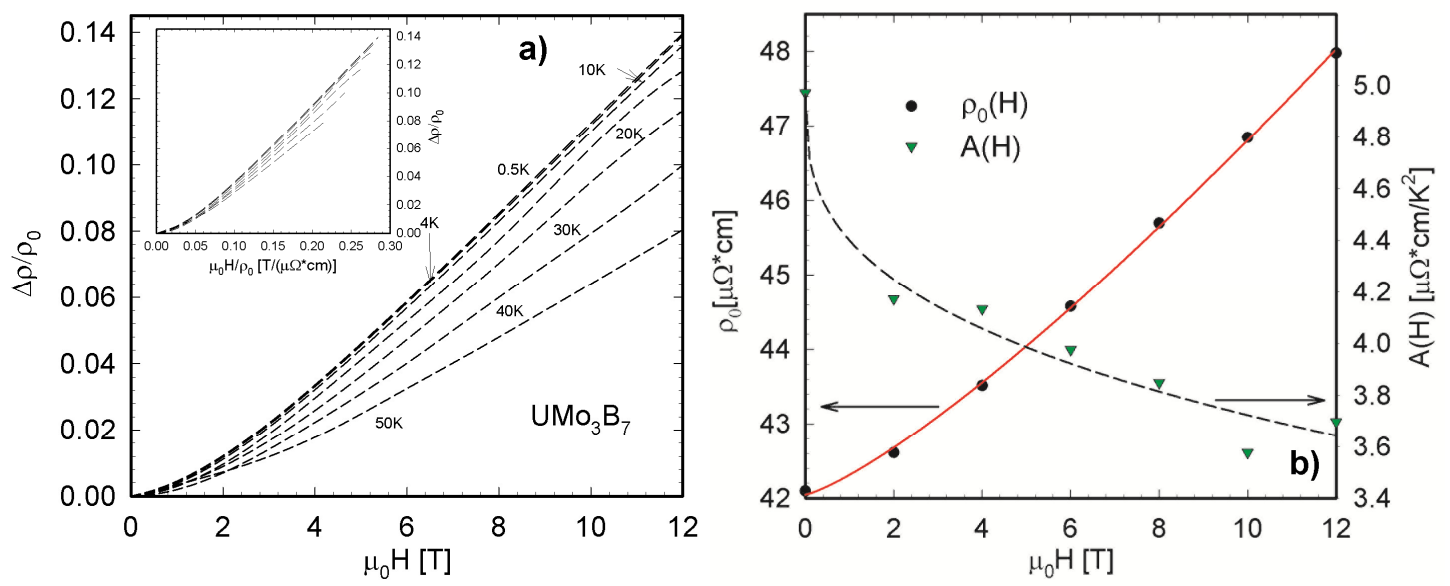

Fig. 5. a) Field dependent magnetoresistance of $\mathrm{UMo}_{3} \mathrm{~B}_{7}$ at various temperatures. The inset shows the Kohler's graph for the same compound. b) Residual resistivity $\rho_{0}$ of $\mathrm{UMo}_{3} \mathrm{~B}_{7}$ together with the temperature independent coefficient $\mathrm{A}(\mathrm{H})$ as a function of external magnetic fields. The solid line corresponds to the fit described in the text. The dashed line is drawn as a guidance for the eye.

For temperatures below $5 \mathrm{~K}$, the behaviour of the electrical resistivity of $\mathrm{UMo}_{3} \mathrm{~B}_{7}$ as a function of magnetic field and temperature is well described by

$$
\rho(H, T)=\rho_{0}(H)+A(H) T^{2} .
$$

Fig. $5 b$ displays the field-dependence of $\rho_{0}$ (left axis). The residual resistivity monotonously increase with increasing fields, $\rho_{0} \propto T^{1.25}$ (see Fig $5 \mathrm{~b}$ ). A(H) decreases with increasing field, taking a rapid drop at low fields but does not show the tendency to saturate in fields up to $12 \mathrm{~T}$. Such a behaviour is common in many spin fluctuating systems, see for example Ref. [31]. 
The temperature dependent magnetic susceptibility of $\mathrm{UMo}_{3} \mathrm{~B}_{7}$ is presented in Figure 6a. The compound exhibits a moderately enhanced (of the order of $10^{-3}$ emu/mol) and almost temperature independent susceptibility, showing no signs of magnetic transitions in the entire temperature range. In the temperature region above $100 \mathrm{~K}$ the data were analyzed using the modified Curie-Weiss law,

$$
\chi=\frac{C}{T-\theta_{p}}+\chi_{0}
$$

delivering the paramagnetic Curie temperature $\theta_{\mathrm{p}}=-45 \mathrm{~K}$ and a temperature independent magnetic susceptibility $\chi_{0}=1.27 * 10^{-3} \mathrm{emu} / \mathrm{mol}$. In the temperature region below $50 \mathrm{~K}$, however, the experimental values of the magnetic susceptibility are lower than those expected from the Curie-Weiss behavior. Subtracting the first term of Eqn. 4 from the approximated experimental data, $\chi_{0}{ }^{*}(\mathrm{~T})$ is found to increase with temperature, reaching $\chi_{0}=1.27 * 10^{-3} \mathrm{emu} / \mathrm{mol}$ at around $70 \mathrm{~K}$.

Fig. $6 \mathrm{~b}$ represents the low temperature dependence of the specific heat $\mathrm{C}_{\mathrm{p}}$ of $\mathrm{UMo}_{3} \mathrm{~B}_{7}$, plotted as $\mathrm{C}_{\mathrm{p}}(\mathrm{T}) / T$ versus $\mathrm{T}^{2}$. Down to $2 \mathrm{~K}$ no evidence of any magnetic ordering was observed, in agreement with resistivity and magnetic susceptibility data. On the other hand, a simple metallic behavior of specific heat, i.e., $\mathrm{C}_{\mathrm{p}}=\gamma T+\beta T^{3}$ is found only for a limited temperature range above $10 \mathrm{~K}$. In the low temperature region the behavior of the specific heat of $\mathrm{UMo}_{3} \mathrm{~B}_{7}$ can be much better approximated by a spin fluctuation model, i.e.,

$$
C_{p}(T)=\gamma T+A T^{3}+B T^{3} \ln \frac{T}{T^{*}},
$$

revealing an enlarged Sommerfeld coefficient $\gamma=28 \mathrm{~mJ} /\left(\mathrm{molK}^{2}\right)$ and a characteristic temperature $T^{*}=6 \mathrm{~K}$. This suspects spin fluctuations in a nearly localized regime. 

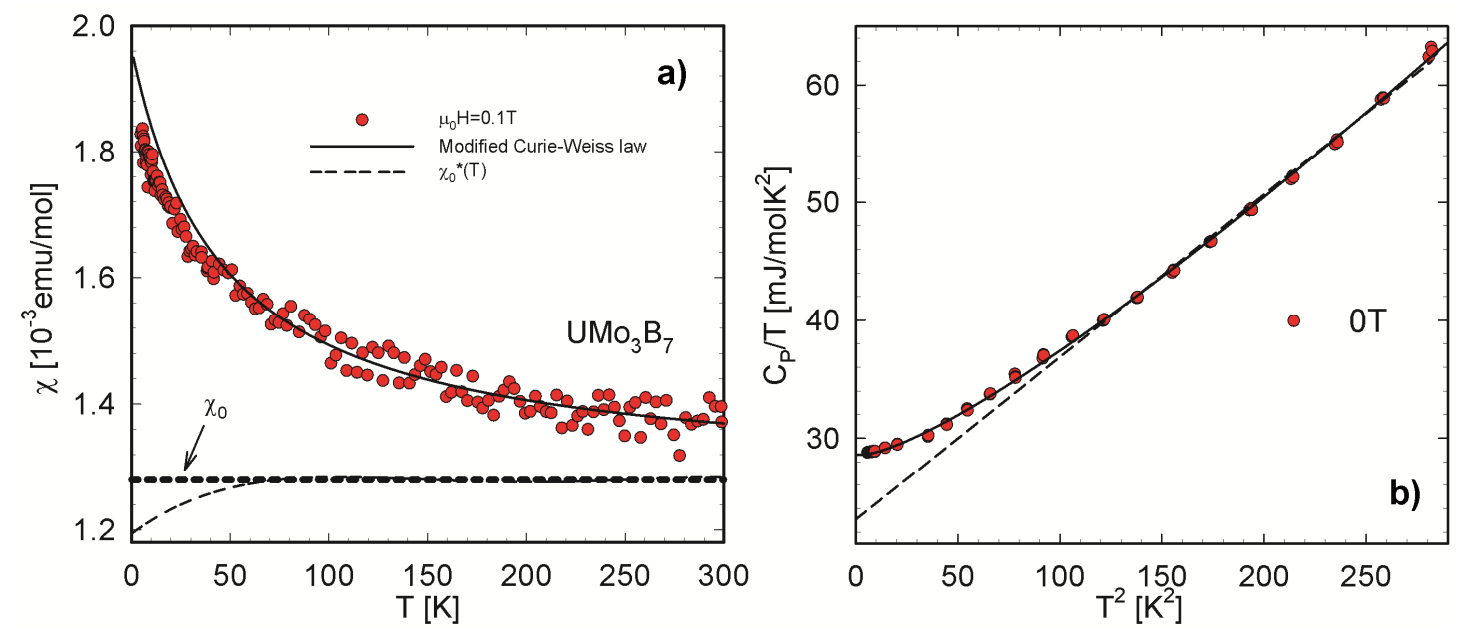

Fig. 6. a) Temperature dependent magnetic susceptibility of polycrystalline $\mathrm{UMo}_{3} \mathrm{~B}_{7}$ measured in a field of $0.1 \mathrm{~T}$. The solid line corresponds to the high temperature modified Curie-Weiss fit as described in the text. The dashed line describes the temperature dependence of $\chi_{0}{ }^{*}(\mathrm{~T})$. b) Low-temperature specific heat $\mathrm{C}_{\mathrm{P}}$ plotted as $\mathrm{C}_{\mathrm{p}}(\mathrm{T}) / T$ vs $\mathrm{T}^{2}$. The solid line is a least-squares fit according to Eqn. 4. The dashed line corresponds to a behaviour according to $\mathrm{C}_{\mathrm{p}}=\gamma T+\beta T^{3}$.

\section{Summary}

A new ternary compound, $\mathrm{UMo}_{3} \mathrm{~B}_{7}$, was identified in the U-Mo-B system at $900{ }^{\circ} \mathrm{C}$. The crystal structure was studied by single crystal X-ray diffraction: $\mathrm{YMo}_{3} \mathrm{~B}_{7}$ type, space group Pnma, $a=1.10310(8) \mathrm{nm}, \mathrm{b}=0.30995(2) \mathrm{nm}, \mathrm{c}=1.2792(1)$. From the relation between the metal:boron ratio [9] and the type of boron atoms linkage established for other boride structures $\left(\mathrm{Er}_{3} \mathrm{CrB}_{7}\right.$ [32], $\mathrm{La}_{2} \mathrm{Re}_{3} \mathrm{~B}_{7}[33,34], \mathrm{W}_{2} \mathrm{Ir}_{3} \mathrm{~B}_{5}$ [35], etc) where the boron atoms form folded infinite chains, the formation of higher boron aggregates in $\mathrm{UMo}_{3} \mathrm{~B}_{7}$ (metal:boron ratio 0.57) is expected. Accordingly, in the $\mathrm{UMo}_{3} \mathrm{~B}_{7}$ the $-\mathrm{B}$ - chains (formed by -B1-B4- at $\mathrm{d}=0.1759 \mathrm{~nm},-\mathrm{B} 3-\mathrm{B} 6-$ at $\mathrm{d}=0.1843$ $\mathrm{nm}$, and -B2-B5- at $\mathrm{d}=0.1762 \mathrm{~nm})$ come close together $\left(\mathrm{d}_{\mathrm{B} 1-\mathrm{B} 3}=0.1796 \mathrm{~nm}, \mathrm{~d}_{\mathrm{B} 2}\right.$ $\left.{ }_{\mathrm{B} 2}=0.1805 \mathrm{~nm}, \mathrm{~d}_{\mathrm{B} 4-\mathrm{B} 7}=0.1807 \mathrm{~nm}, \mathrm{~d}_{\mathrm{B} 5-\mathrm{B} 6}=0.1813 \mathrm{~nm}\right)$ to build $6^{3}$ boron bands. Considering the metal atoms framework, $\mathrm{UMo}_{3} \mathrm{~B}_{7}$ has common fragments with the structure of $\mathrm{CrB}$ : B-filled trigonal prisms, and unfilled tetrahedra and tetragonal pyramids.

$\mathrm{UMo}_{3} \mathrm{~B}_{7}$ does not exhibits long range magnetic order above $500 \mathrm{mK}$. Rather a spin fluctuation scenario characterizes the low temperature behavior of resistivity, 
magnetic susceptibility and specific heat of this compound, resulting in a moderately enlarged Sommerfeld value $\gamma=28 \mathrm{~mJ} /\left(\mathrm{molK}^{2}\right)$.

ACKNOWLEGMENTS. Research supported by Austrian National Science Foundation FWF V279-N19. L.S. is thankful to OÄD for a fellowship. This work was partially supported in Portugal with funds from FEDER (Programa Operacional Factores de Competividade COMPETE-2020) and from FCT - Fundação para a Ciência e Tecnologia under projects Nb 016789 PTDC/FIS-NAN/6099/2014 and UID/Multi/04349/2013. 


\section{References}

[1] S. Souma, Y. Machida, T. Sato, T. Takahashi, H. Matsui, S.C. Wang, H. Ding, A. Kaminski, J.C. Campuzano, S. Sasaki, K. Kadowaki, The origin of multiple superconducting gaps in $\mathrm{MgB}_{2}$, Nature 423 (2003) 65-65.

[2] J. Nagamatsu, N. Nakagawa, T. Muranaka, Y. Zenitani, J. Akimitsu, Superconductivity at $39 \mathrm{~K}$ in magnesium diboride, Nature 410 (2001) 63-64.

[3] S. Nakatsuji, K. Kuga, Y. Machida, T. Tayama, T. Sakakibara, Y. Karaki, H. Ishimoto, S. Yonezawa, Y. Maeno, E. Pearson, G.G. Lonzarich, L. Balicas, H. Lee, Z. Fisk, Superconductivity and quantum criticality in the heavy-fermion system $\boldsymbol{\beta}$ $\mathrm{YbAlB}_{4}$, Nature Physics 4 (2008) 603-607.

[4] R.T. Macaluso, S. Nakatsuji, K. Kuga, E.L. Thomas, Y. Machida, Y. Maeno, Z. Fisk, J.Y. Chan, Chem. Mater. Crystal structure and physical properties of polymorphs of $\mathrm{LnAlB}_{4}(\mathrm{Ln}=\mathrm{Yb}, \mathrm{Lu}) 19$ (2007) 1918-1922.

[5] Y. Matsumoto, S. Nakatsuji, K. Kuga, Y. Karaki, N. Horie, Y. Shimura, T. Sakakibara, A.H. Nevidomskyy, P. Coleman, Quantum criticality without tuning in the mixed valence compound $\beta-\mathrm{YbAlB}_{4}$, Science 331 (2011) 316-319.

[6] K. Yubuta, T. Mori, S. Okada, Yu. Prots, H. Borrmann, Yu. Grin, T. Shishido High-resolution electron microscopy and X-ray diffraction study of intergrowth structures in $\alpha$ - and $\beta$-type $\mathrm{YbAlB}_{4}$ single crystals, Philosophical Magazine, 93 (2013) 1054-1064.

[7] D.A. Tompsett, Z.P Yin, G.G. Lonzarich, W.E. Pickett, Role of crystal symmetry in the magnetic instabilities of $\beta-\mathrm{YbAlB}_{4}$ and $\alpha-\mathrm{YbAlB}_{4}$, Phys. Rev. B 82 (2010) 235101.

[8] Yu.B. Kuz'ma, S.I. Svarichevskaya, Crystal structure of compounds $\mathrm{Y}_{2} \mathrm{ReB}_{6}$ and their analogous, J. Sov. Phys. Crystallogr. 17 (1972) 569-571.

[9] P. Rogl, Existence and Crystal Chemistry of Borides, in: J.J. Zuckerman (Ed.), Inorganic Reactions and Methods, VCH-Publications Inc., 1991, 13(6), 85-167 and references therein.

[10] A.M. Alekseeva, A.M. Abakumov, P.S. Chizhov, A. Leithe-Jasper, W. Schnelle, Yu. Prots, J. Hadermann, E.V. Antipov, Yu. Grin, Ternary magnesium rhodium boride $\mathrm{Mg}_{2} \mathrm{Rh}_{1-\mathrm{x}} \mathrm{B}_{6+2 \mathrm{x}}$ with a modified $\mathrm{Y}_{2} \mathrm{ReB}_{6}$-type crystal structure, Inorg. Chem. 46 (2007) 7378-7386. 
[11] A.M. Alekseeva, Yu. Prots, A. Leithe-Jasper, E.V. Antipov, Yu. Grin, Crystal structure of magnesium iridium boride, $\operatorname{Mg}_{2} \operatorname{Ir}_{1-\mathrm{x}} \mathrm{B}_{6+2 \mathrm{x}}(\mathrm{x}=0.3)$, Z. f Kristallogr. - New Crystal Structures 224 (2009) 19-20.

[12] T. Mori, T. Shishido, K. Yubuta, K. Nakajima, A. Leithe-Jasper, Yu. Grin, Physical properties of $\beta-\mathrm{TmAlB}_{4}$ an $\mathrm{AlB}_{2}$-type analogous "tiling" compound, J. Appl. Phys. 107 (2010) 09E112-3.

[13] T. Mori, S. Okada, K. Kudou, Magnetic properties of thulium aluminoboride TmAlB 4 , J. Appl. Phys. 97 (2005) 10A910-3.

[14] T. Mori, H. Borrmann, S. Okada, K. Kudou, A. Leithe-Jasper, U. Burkhardt, Yu. Grin, Crystal structure, chemical bonding, electrical transport, and magnetic behavior of $\mathrm{TmAlB}_{4}$, Phys. Rev. B 76 (2007) 064404.

[15] I.P. Valyovka, Yu.B. Kuzma, Isothermal section of the diagram of the systems U-Mo-B and U-Re-B, Sov. Powder Metall. Met. Ceram. 25 (1986) 986-988.

[16] P. Rogl, H. Nowotny, Complex borides with uranium, Monatsh. Chem. 106 (1975) 381-387.

[17] P. Rogl, L. DeLong, New ternary transition metal borides containing uranium and rare earth elements, J. Less-Common Met. 91 (1983) 97-106.

[18] T. Konrad, W. Jeitschko, $\mathrm{U}_{5} \mathrm{Mo}_{10} \mathrm{~B}_{24}$, a boride containing three different kinds of boron polyanions, J. Alloys Comp. 233 (1996) L3-L7.

[19] L Salamakha, C Rizzoli, S Mudryi, M Almeida, U-Mo-B System: Phase Equilibria at $900^{\circ} \mathrm{C}$ and Crystal Structure of Compounds, 43èmes Journées des Actinides, 6-9 April 2013, Sestri Levante, Italy

[20] T. Roisnel, J. Rodriguez-Carvajal, 2000 WinPLOTR: a Windows tool for powder diffraction patterns analysis, in: R. Delhez, E.J. Mittenmeijer (Eds.) Materials Science Forum, Proceedings EPDIC 7 (2000) 118-123.

[21] J. Rodriguez-Carvajal, Recent advances in magnetic structure determination by neutron powder diffraction, Physica B 192 (1993) 55-69.

[22] SMART, SAINT, and SADABS Packages. Version 5.1. Bruker AXS. Madison WI 1997-1999.

[23] G.M. Sheldrick, A short history of SHELX, Acta Cryst. A64 (2008) 112-122.

[24] L.J. Farrugia, Win $G X$ suite for small-molecule single-crystal crystallography, J. Appl. Cryst. 32 (1999) 837-838. 
[25] E. Bauer, St. Berger, Ch. Paul, M. Della Mea, G. Hilscher, H. Michor, M. Reissner, W. Steiner, A. Grytsiv, P. Rogl, E.-W. Scheidt, Crystal field effects and thermoelectric properties of $\mathrm{PrFe}_{4} \mathrm{Sb}_{12}$ skutterudite, Phys Rev B 66 (2002) 214421.

[26] E. Parthé, L. Gelato, B. Chabot, M. Penzo, K. Censual, R. Gladyshevskii, TYPIX -Standardized Data and Crystal Chemical Characterization of Inorganic Structure Types, Gmelin Handbook of Inorganic and Organometallic Chemistry, 8th edition (1994).

[27] S.I. Mikhalenko, V.S. Babizhetskii, H. Hartl, Yu.B. Kuzma, New $\mathrm{YMo}_{3} \mathrm{~B}_{7}$ boride and its structure, Crystallogr. Rep. 40 (1995) 424-427.

[28] R. Keissling, The binary system chromium - boron, Acta Chem Scand 3 (1949) 595-602.

[29] K.E. Spear, P.W. Gilles, Phase and structure relationships in the vanadium-boron system, High Temp. Sci. 1 (1969) 86-97.

[30] D. Hohnke, E. Parthé, $A B$ compounds with $\mathrm{Sc}, \mathrm{Y}$ and rare earth metals. II. FeB and $\mathrm{CrB}$ structures of monosilicides and germanides, Acta Cryst. 20 (1966) 572-582.

[31] K. Ikeda, K.A. Gschneidner Jr., N. Kobayashi, K. Noto, Magnetoresistance of $\mathrm{Sc}_{3} \mathrm{In}$, J. Magn. Magn. Mater. 42 (1984) 1-11.

[32] N.F. Chaban, L.G. Aksel'rud, V.A. Bruskov, Yu.B Kuz'ma, Crystal structure of the new boride $\mathrm{Er}_{3} \mathrm{CrB}_{7}$, Sov. Phys. Crystallogr. 30 (1985) 108-109.

[33] Yu.B. Kuzma, S.I. Mykhalenko, B.Ya. Kotur, Ya.P. Yarmolyuk, The crystal structure of boride $\mathrm{La}_{2} \mathrm{Re}_{3} \mathrm{~B}_{7}$, Dopov. Akad. Nauk Ukr. RSR B 3 (1982) 24-27.

[34] D.E. Bugaris, Ch.D. Malliakas, D.Y. Chung, M.G. Kanatzidis, Metallic Borides, $\mathrm{La}_{2} \operatorname{Re}_{3} \mathrm{~B}_{7}$ and $\mathrm{La}_{3} \mathrm{Re}_{2} \mathrm{~B}_{5}$, Featuring extensive boron- boron bonding, Inorg. Chem. 55 (2016) 1664-1673.

[35] P. Rogl, F. Benesovsky, H. Nowotny, Complex borides with platinum metals, Monatsh Chem 103 (1972) 965-989. 